\title{
DISCURSO DE POSSE DA PROFESSORA IVETTE SENISE FERREIRA COMO DIRETORA DA FACULDADE DE DIREITO DA UNIVERSIDADE DE SÃO PAULO
}

Estamos nesta data reunidos, tanto a comunidade acadêmica quanto as pessoas das mais variadas origens e condições que aqui se encontram, para um rito de passagem e uma celebração. Um rito de passagem que segue a rotina das transmissões de cargo na Faculdade de Direito da Universidade de São Paulo, que ora recebe o seu $37^{\circ}$ Diretor, no caso uma Diretora, pela primeira vez em seus 170 anos de existência, desde a sua fundação pelo imperador Dom Pedro I, em 11 de agosto de 1827 Mas, não-só por isso, é este também um momento de celebração, com grande significado na história desta Instituição, por se tratar da última transmissão da Diretoria neste século, prestes a findar-se, e a primeira a inaugurar, no século XXI, a Nova Era que se prenuncia prenhe de vertiginosas mudanças para as quais devemos nos preparar.

As alegrias desse acontecimento que o Destino me proporcionou nesta etapa da minha trajetória de vida foram sobremaneira intensificadas pela possibilidade, que também me foi concedida, de ser saudada por um dos mais brilhantes professores desta Casa, o embaixador Celso Lafer, remanescente das nossas tradições de cultura humanística e intelectual, da mais pura linhagem do saber, figura ímpar de simpatia e amabilidade, que trilhou com desenvoltura e competência os campos da Filosofia e da Economia, da Administração e da Ciência Política, além do Direito Internacional, tendo agora enveredado pelos difíceis caminhos da diplomacia, ao representar o nosso País como embaixador-chefe da Missão Permanente do Brasil em Genebra junto à $\mathrm{ONU}$ e à $\mathrm{OMC}$.

Honrou-me o professor Celso Lafer com uma saudação primorosa, cumulando-me de elogios e atribuindo-me qualidades por mim insuspeitadas, deixando transparecer os laços de amizade estabelecidos pelo longo convívio acadêmico, desde o momento em que travei conhecimento com o jovem mestre, de inteligência fulgurante, que nos ministrava, na pós-graduação desta Faculdade, um excelente Curso sobre Organizações Internacionais, e que depois me submeteria ao crivo de suas argüições no meu doutoramento, para mais tarde revelar-se excelente amigo, disposto a impulsionar-me, como a todas as mulheres desta Casa, para a conquista de espaços antes inatingíveis. 
Não poderia ser outro o seu proceder perante o universo feminino, já que a sua personalidade e a sua formação intelectual haviam sido influenciadas por uma grande Mulher, sua professora Hannah Arendt, a quem demonstra em todas as ocasiões o seu respeito e a fidelidade às idéias e opiniões por ela expendidas.

$\mathrm{Na}$ verdade, o pensamento dessa notável filósofa e a temática que desenvolveu com base nas suas inquietações perante os problemas do mundo contemporâneo, que ela transmitiu aos seus discípulos os quais, como Celso Lafer, por sua vez as retransmitiram, são bastante apropriados para este final de milênio, momento de transição em que se impõe uma reavaliação do que fizemos, do que somos e do que queremos para as futuras gerações. Cabem aqui as reflexões por ela feitas em sua obra "Entre o Passado e o Futuro", em que analisa os dilemas do mundo moderno em confronto com a Tradição, particularmente adequadas nesta Casa, berço de tantas tradições, cenário de tantas lutas e reivindicações, baluarte da liberdade e da defesa dos direitos humanos, templo do Direito e da Justiça.

São idênticas as nossas preocupações de conferir a necessária dignidade à Política, e de impedir a diluição da Tradição para evitar a lacuna entre o passado e o futuro, apontadas por ela no seu livro "As Origens do Totalitarismo" Semelhantes às suas são as nossas inquietações com o esfacelamento dos padrões morais que estão na base dos conflitos do mundo contemporâneo e da sociedade moderna, minuciosamente examinados em sua obra "A Condição Humana" Pensamos também que a desvalorização dos valores, característica da cultura de massas, é um processo que devemos impedir para restaurar certos conceitos deturpados no mundo contemporâneo, como o da relação entre a verdade factual e a Política, o da liberdade quando desarticulada da sua interação com os outros, e também para obstar certas práticas como a manipulação da opinião pública pelos técnicos da comunicação, e a instauração da violência nas ações mais comezinhas, produzindo a sua banalização na sociedade.

Concordamos ainda quando preconiza $o$ agir de preferência ao fazer, pois a ação traduz movimento, atividade no seu exercício contínuo, enquanto que o fazer exprime atividade executada num determinado instante. E quando pondera que a ação deve necessariamente ser inserida num contexto, cujo sentido é fornecido pelo conceito de autoridade, que nos foi legado pelos romanos, mas que deve ser revisto no momento atual em que nos defrontamos com uma crise de autoridade, tanto no mundo político quanto na vida cotidiana, que leva muitos à crença do seu desaparecimento na época moderna. Essa crise, de origem política, espalhou-se por 
outras áreas como a criação dos filhos e a educação onde sempre fora aceita como fenômeno natural e necessário, atingindo também a religião e as tradições em geral.

No limiar de uma Nova Era impõe-se a revisão do conceito de autoridade para que se definam os rumos que serão estabelecidos para as gerações vindouras, o qual implica necessariamente numa obediência que no entanto não é mais cega, mas na qual se pode reter uma parcela de liberdade que lhe dará o sentido de uma ação conjunta. Segundo Arendt é essa ação conjunta que faz avançar e viver as instituições e que inspira os feitos e acontecimentos da ação futura.

Esta crise de autoridade, como outras crises de valores que hoje nos assolam, certamente irão provocar o surgimento de novas idéias e teorias, revitalizando os juízos já formados, dando oportunidade para reflexões que nos aproximem da experiência da realidade, tão-necessária no mundo do Direito. Por isso a formação do jurista deve levar em conta o seu papel social, atribuindo-se à investigação jurídica novas dimensões, no sentido preconizado por Norberto Bobbio, de uma profunda reformulação dos estudos do Direito para buscar respostas aos problemas surgidos na época contemporânea com idéias e posicionamentos inovadores que não descartem porém o rigor e a disciplina de pensamento para evitar que as normas sejam violadas ou que a sua violação produza graves conseqüências.

Talvez, por ser eu penalista, as idéias de Bobbio e a sua Teoria do Ordenamento Jurídico seduziram-me, notadamente porque propõem uma função promocional para as normas jurídicas com o estabelecimento de sanções positivas, ou normas de encorajamento para certas condutas, numa forma de controle social persuasivo e premonitivo em que adquire especial importância o aumento das medidas preventivas sobre as repressivas. Tais concepções de certo modo já se refletem no Direito Penal moderno com a reformulação do tradicional sistema de penas e das finalidades meramente repressivas das cominações para acolher novas formas de retribuição, nem sempre bem-aceitas por todos, mas que representam a fórmula salvadora para um sistema que se comprovou ser ineficiente e incapaz de impedir o aumento da criminalidade nos tempos atuais.

Esse posicionamento não pode deixar de produzir conseqüências na Ciência Jurídica de uma sociedade em transformação, alterando a tradição do Estado protetor e repressor, como bem aponta Tércio Sampaio Ferraz Júnior, para, sem desprezar as suas características dogmáticas, transformar o Direito num conjunto de regras com função implementadora de comportamentos, às quais se assinala um papel modificador e criador. É claro que a investigação jurídica adquire assim novas 
dimensões, ganhando um cunho interdisciplinar a ser considerado na própria formação do jurista, e portanto do ensino do Direito, que se volta cada vez mais para indagações sociológicas, econômicas e políticas.

Revitalizar o Direito e aproximá-lo das necessidades atuais da sociedade neste final de século é uma das contribuições possíveis desta Faculdade que sempre soube exercer a sua vocação de liderança, desde a sua criação. Aqui foram forjados grandes estadistas e juristas que se projetaram no cenário político e discutiram os grandes problemas nacionais, como a abolição da escravatura e a instauração da República no Brasil, entre os quais avultam Prudente de Morais, Campos Sales, José Maria Paranhos o Barão do Rio Branco, Joaquim Nabuco, Rui Barbosa e José Bonifácio, o Moço, entre tantos outros... Desde o final do século passado, com Rodrigues Alves e Afonso Pena, aqui se produziu vários presidentes da República, cuja contribuição ao desenvolvimento da Nação a história julgará no futuro. Em todas as áreas do Direito o pensamento jurídico evoluiu com a contribuição de professores e alunos desta Casa, tantos e tão-ilustres que aqui não cabe enumerá-los.

A cultura brasileira em geral, sem modéstia, conosco se enriqueceu em todos os domínios, numa demonstração clara de que não-só à carreira jurídica se destinam os acadêmicos do Largo de São Francisco, os quais se espalham pelos mais variados campos, daqui tendo saído inúmeros escritores, poetas, romancistas, ensaístas, historiadores, jornalistas, sociólogos e, por que não, até mesmo economistas, numa infinidade de nomes que figuram nas estantes das bibliotecas e nas placas das ruas da Cidade.

Nestas especiais circunstâncias, porém, cabe indagar: e as mulheres desta Casa? Essa curiosidade é aguçada pelo fato de hoje uma delas estar assumindo a sua direção, pela primeira vez, numa evidente demonstração de que as coisas aqui já não são mais como antes...

Sem querer fazer aqui um estudo da condição feminina e da sua evolução através dos tempos, cumpre-nos observar que a mulher historicamente sempre teve um status diferente do homem, baseado preponderantemente na sua capacidade produtora e reprodutora. Isso originou uma certa divisão do trabalho na sociedade e na família, traduzindo-se essa diferença biológica e social numa posição de inferioridade que perdurou através dos tempos.

A escritora portuguesa Maria Antonia Palla, em sua obra " $A$ Condição Feminina" assinala que no decorrer dos séculos e nas várias sociedades esse papel 
variou e que a evolução não se fez de forma linear, mas é certo que a partir da Revolução Industrial, no século XIX, a transformação positiva das sociedades está ligada à conquista de uma maior liberdade e igualdade entre os cidadãos, homens e mulheres, cabendo ao século XX a criação das condições para a eliminação de todas as discriminações existentes no seu status, sob o impulso das organizações internacionais que pressionaram os Governos dos diferentes países a adotar instrumentos para a implementação da igualdade de direitos e oportunidades entre as pessoas dos dois sexos.

Inegavelmente contribuiu para essa evolução o esforço das feministas que tentavam modificar as idéias existentes sobre a natureza da mulher, assegurando que as diferenças entre homens e mulheres decorrem menos da sua fisiologia do que dos papéis que estas foram obrigadas a desempenhar na sociedade, sendo por isso culturais e não-biológicas. Daí a afirmação extremada de Simone de Beauvoir, em meados deste século: "On ne nait pas femme, on le devient"

A questão que se coloca porém não é essa, mas sim a que Maria Antonia Palla muito bem formulou: "A serem diferentes os homens e as mulheres, terá fatalmente essa diferença de se exprimir em termos de desigualdade?"

Evelyne Sullerot, escrevendo em 1970 sobre "A Mulher no Mundo Moderno" baseia-se no fato científico da diferença biológica entre homens e mulheres e defende a igualdade na diferença. As mulheres, diz ela, devem procurar tirar vantagens dos seus dons específicos sem perderem a oportunidade de desenvolver todas as suas potencialidades: daí a importância que assume a sua formação profissional, mola-mestra da modificação dos papéis historicamente assumidos pela mulher, que nada tem a ver com o desenvolvimento científico e tecnológico - com todos os meios que coloca à disposição da mulher. Para isso contribuem também inegavelmente os meios de comunicação de massa que, além de permitirem uma compreensão mais vasta desses problemas, geram uma consciência mais generalizada da necessidade e das possibilidades dessa evolução.

Essa evolução, que se originou do ingresso maciço das mulheres no mercado de trabalho pelas necessidades do desenvolvimento industrial, desde o século XIX, passou pelo direito de voto, reconhecido às mulheres sucessivamente, nos vários países a partir do início deste século até 1971, quando a Suíça finalmente se rendeu à orientação geral, e finalmente atingiu o estágio em que quase todas as profissões abriram o acesso às mulheres diminuindo os redutos de discriminação. Algumas, como Golda Meir, Indira Gandhi e depois Margaret Thatcher chegaram a 
ocupar altos cargos governamentais, sendo intensificada e estimulada a atuação feminina na Política pelos Atos e Declarações internacionais, que incluem a aprovação, em 1979, pela Assembléia Geral da ONU, de uma Convenção sobre a Eliminação de todas as formas de Discriminação contra as Mulheres, ratificada pela maioria das nações civilizadas, inclusive pelo Brasil, na mesma linha da anterior "Declaração sobre a Eliminação da Discriminação contra as Mulheres", adotada pelas Nações Unidas, em 1967, que reúne num único texto todas as questões referentes aos direitos políticos, sociais e culturais das mulheres.

A realidade histórica da mulher foi sendo assim modificada, necessitando de novas avaliações, exigidas pelas suas constantes mutações que envolvem também o homem, porque um e outro são duas formas de vida irredutíveis mas inseparáveis, referidas uma à outra.

Um notável filósofo espanhol Julian Marías, em obra percuciente sobre " $A$ Mulher no Século $X X$ " afirma que a grande ampliação das possibilidades femininas não ocorreu antes que a mulher tivesse pleno acesso à cultura universitária, cujo equivalente havia sido patrimônio de mulheres excepcionalmente bem-dotadas e nascidas nos cimos da sociedade européia, como Isabel, a Católica, ou a rainha Cristina da Suécia, ou então das mulheres individualmente "emancipadas" da época romântica.

A incorporação da mulher à cultura universitária que aconteceu primeiro nos Estados Unidos da América do Norte, mais tarde na Europa e, com algum atraso, na América Latina, contribuiu decisivamente para a evolução que se produziu na situação da mulher a partir do século XIX, com efeitos na própria estrutura da sociedade pela ampliação do número de universitários no corpo social em geral, passando homens e mulheres a viver no mesmo mundo histórico, cultural, político e público, criando uma nova e original forma de convivência que levou a um nivelamento, segundo Julian Marías, "a uma atenuação da diferença de potencial entre eles, ao tornar-se habitual o que era infreqüente, ao converter-se em algo rotineiro":

Nesta Faculdade especificamente tivemos a nossa precursora ainda no século passado, quando Maria Augusta Saraiva matriculou-se no curso de Direito, em 1898, sendo a primeira advogada a se formar pelo Largo de São Francisco, em 1902, a quem rendemos aqui as nossas homenagens pelo valor e pela audácia demonstradas. Esse acontecimento porém só voltaria a se repetir em 1909, quando aqui se bacharelaram, na mesma turma de Cásper Líbero e Manoel Carlos de 
Figueiredo Ferraz, a dupla Maria Andréa e Maria Luiza de Oliveira, talvez irmãs, quem sabe, e depois, em 1911, apenas Eudoxia de Castro.

Nos anos seguintes, enquanto os homens formados nas Arcadas iam se tornando figuras ilustres as mulheres continuaram ausentes das colações de grau, a não ser por Walkyria Moreira da Silva, em 1913. A Faculdade continuava a ser uma Academia masculina, fornecendo a significativa contribuição de seus bacharéis à vida pública do País, à literatura, ao jornalismo, às carreiras jurídicas e à docência no ensino do Direito. Somente em 1925 irá aparecer um nome feminino na relação dos formandos, o de Maria Immaculada Xavier da Silveira, aumentando para três em 1926, quando se graduam Celeste Sampaio Vianna, Regina Cecilia Nolf Nazario e Ruth de Assis.

No ano de 1927, em que se comemorou o centenário da fundação da Faculdade, sendo presidente da República Washington Luiz Pereira de Souza, apenas Adalzira Bittencourt recebia o seu grau de bacharel, e somente em 1929 registra-se a passagem por aqui de uma "linda e encantadora loura" Clementina Cataldi, na turma de nossos mestres Joaquim Canuto Mendes de Almeida e Philomeno Joaquim da Costa. Outros nomes femininos somente irão aparecer em 1934, com a formatura de Amélia Duarte e de Iracema Tavares Dias, da turma do nosso eminente professor Miguel Reale. Este ano, deve-se observar, marca a transferência desta Faculdade da esfera federal para o Governo de São Paulo, vindo ela, em 1935, a fazer parte, juntamente com outros institutos, do núcleo inicial da Universidade de São Paulo, em meio às obras de reconstrução do edifício antigo em que estava instalada, que virão lhe dar a configuração atual.

Essa enumeração, que pode parecer a alguns enfadonha, tem por intuito mostrar quão-lento foi o ingresso das mulheres na vida universitária nessa área, nas gerações que precederam a minha existência neste mundo, e por conseguinte o seu processo de nivelação nas carreiras jurídicas e a sua aceitação pela comunidade masculina.

A parcimônia da presença do elemento feminino perdurou ainda por algum tempo nesta Faculdade, enquanto eu crescia para a vida e iniciava a minha educação básica, somente se modificando a situação na década de 40 , em que se verifica uma progressão um pouco maior, que se tornaria mais rápida nos anos subseqüentes. Em 1944, entre as seis mulheres que se diplomaram estava a nossa querida professora Esther de Figueiredo Ferraz, que depois serviria de exemplo para as suas alunas, pois com o seu pioneirismo e a sua coragem inaugurou neste século 
uma nova era para a mulher profissional do Direito ao projetar-se primeiro como brilhante advogada no foro de São Paulo, onde ainda hoje atua, e depois como docente desta Casa, por concurso de títulos e provas em que venceu a discriminação existente pela competência e pelos conhecimentos demonstrados, para depois dedicar-se mais profundamente à educação em nível administrativo, sempre abrindo caminhos como primeira ocupante, na Reitoria da Universidade Mackenzie e no Ministério da Educação, depois de ter sido também secretária da Educação do Estado de São Paulo. Rendo aqui as minhas homenagens e a minha gratidão, pelos ensinamentos e pelo exemplo, à dileta Mestra, depois colega e amiga, que me apoiou e me guiou em todas as horas.

A invasão feminina passou a ser contínua desde então, estendendo-se à carreira docente, a princípio timidamente e depois com a segurança da verificação de que os tempos estavam mudando e com eles os costumes, os hábitos e as mentalidades, diminuindo as resistências nos redutos conservadores, que abrangiam não-só as Academias mas também as outras entidades onde se exerciam as carreiras jurídicas. As professoras Esther de Figueiredo Ferraz e Nair Lemos Gonçalves foram as pioneiras e figuras exponenciais desse período de transição, sendo a segunda a primeira mulher a ocupar a vice-Diretoria nesta Casa, avanço considerável, dadas as circunstâncias.

No ano de 1957, quando a professora Ada Grinover e eu concluímos o nosso curso de Direito, o número de mulheres já impressionava e prenunciava as mudanças que depois ocorreriam, com 65 delas recebendo o grau de bacharel em Ciências Jurídicas e Sociais, numa proporção de $20 \%$ em relação à totalidade da Turma, que hoje já subiu para mais de $50 \%$. Essa nova situação não-só favoreceu o aumento da participação feminina no quadro docente desta e de outras Faculdades de Direito, mas também propiciou o alargamento das possibilidades de ingresso, aos poucos, em todas as carreiras da área jurídica, eliminando na prática qualquer resquício de discriminação que restasse com relação às mulheres no exercício de sua profissão, inclusive nas funções de chefia, como comprovam a passagem da professora Myriam Krasilchik na vice-Reitoria da USP, na gestão anterior e a da professora Ada Grinover na pró-Reitoria de Graduação, na gestão atual, assim como a da professora Odete Medauar na vice-Diretoria desta Faculdade, até hoje Diretora em exercício, e a minha própria eleição e nomeação para a mesma Diretoria.

Assumo, pois, a Direção desta Casa na conclusão de um processo irreversível de transformação a que foi submetida esta tradicional Instituição de 
Ensino derivado das mudanças havidas na sociedade, em decorrência do próprio Direito que passou a assegurar a igualdade de todos perante a lei, que na prática se traduz por igualdade de oportunidades baseada apenas na capacidade individual, na competência e no preparo profissional como critérios a serem privilegiados.

Por uma conjugação de circunstâncias, e feliz coincidência, a Faculdade de Direito da Universidade de São Paulo, ao completar os seus 170 anos de existência, tem a honra de ter não-somente uma mas três figuras femininas dirigindo os seus destinos, pois além da Diretora recém-empossada e da viceDiretora que permanece no cargo, uma outra mulher ocupa, também pela primeira vez, a presidência da sua agremiação estudantil, o igualmente tradicional Centro Acadêmico XI de Agôsto, a estudante Andréa Mustafa. São fatos que falam por si mesmo e demonstram que todos nesta Academia estão concordes neste redimensionamento salutar que certamente produzirá os seus frutos no próximo milênio.

Não desejo alongar-me mais nesta manifestação inaugural da minha gestão, que, avançando até o ano de 2002, certamente apresentará outras ocasiões de reavaliar as mudanças da passagem do século. Todavia quero ainda consignar aqui os meus agradecimentos a todos aqueles que contribuíram para que este momento acontecesse: ao Magnífico Reitor, pela consideração dedicada à minha pessoa e pela confiança demonstrada ao escolher o meu nome na lista tríplice que lhe foi submetida; aos professores, alunos e funcionários que me concederam o seu voto possibilitando que essa escolha fosse feita; ao meu caríssimo Diretor, professor Álvaro Villaça Azevedo, e à querida vice-Diretora, professora Odete Medauar, pelo apoio e estímulo na conquista efetuada; aos colegas que me distinguiram com a sua amizade e o seu incentivo em todas as etapas da minha trajetória universitária, e que hoje aqui comparecem para a sua comprovação; aos meus alunos, da graduação e da pós-graduação, cuja atenção, compreensão e apreço constituíram um encorajamento para que eu prosseguisse na carreira docente e condição para que eu aqui chegasse; aos meus familiares, pelo apoio incondicional em todos os momentos, pelo auxílio e compreensão frente aos percalços encontrados no caminho, especialmente às minhas filhas, aqui presentes, que souberam entender a impossibilidade da minha presença constante em suas vidas, às quais dedico esta vitória como nossa vitória comum; aos meus pais, com quem aprendi que todo sacrifício vale a pena quando o objetivo é nobre e justo; aos meus amigos, fãs irrecuperáveis que aqui estão para demonstrar os laços antigos ou recentes que nos unem e que sempre me concederam não-somente o 
seu aplauso, mas também comoventes demonstrações de carinho e fé nos meus propósitos e na minha capacidade; às autoridades que aqui se encontram para me prestigiar nesse feito, enfim a todos os que aqui acorreram para, com sua presença, fazer desta uma noite memorável!

Para encerrar, quero ainda homenagear esta Casa, por cujas Arcadas transitei durante mais da metade da minha existência e onde aprendi a cultuar os valores pelos quais norteio a minha vida. Nada mais apropriado para isso do que repetir aqui as palavras de um grande poeta, aqui presente, que como eu a ela se ligou por perenes laços de dedicação e afeto, que ele soube expressar tão-bem com seus versos, os quais me permito tomar de empréstimo, porque pertinentes, no trecho mais comovente do seu "Canto de Amor à Faculdade" Do nosso acadêmico Paulo Bonfim:

"Somos passado e futuro,

Presente de indagações,

Pedra de sonhos crescendo

No Largo de São Francisco;

Canção de velhas violas

Embalando cosmonautas,

Arcadas que o tempo arcou

Para que delas partissem

Flechas de amor e protesto,

Setas com plumas de dor

E pontas de inconformismo.

-Em vossos olhos o olhar

Das gerações que partiram,

Das gerações que virão.

Em vossa luz a palavra

Estrela de tanta noite!

Em vossas mãos a bandeira

Bordada por vossos mortos,

Bandeira que é céu de Pátria,

Terra prenhe de esperança,

Canção de guerra e de paz

Na audácia de vossas lanças!

-Pela memória da terra, 
Pelos segredos do Pátio,

Pela prece das arcadas,

Pela aurora das paredes,

Pelo mistério das salas,

Pelo grito das estátuas,

Pela voz da escadaria,

Pela clareira do Largo,

Pela benção dos telhados,

Pela alma dos poetas,

Pelo martírio de heróis,

Por tudo que é São Francisco,

Por tudo que é mocidade,

Seja nossa vossa causa

Seja vossa nossa luta!"

(Arcadas, 10 de agosto de 1998) 



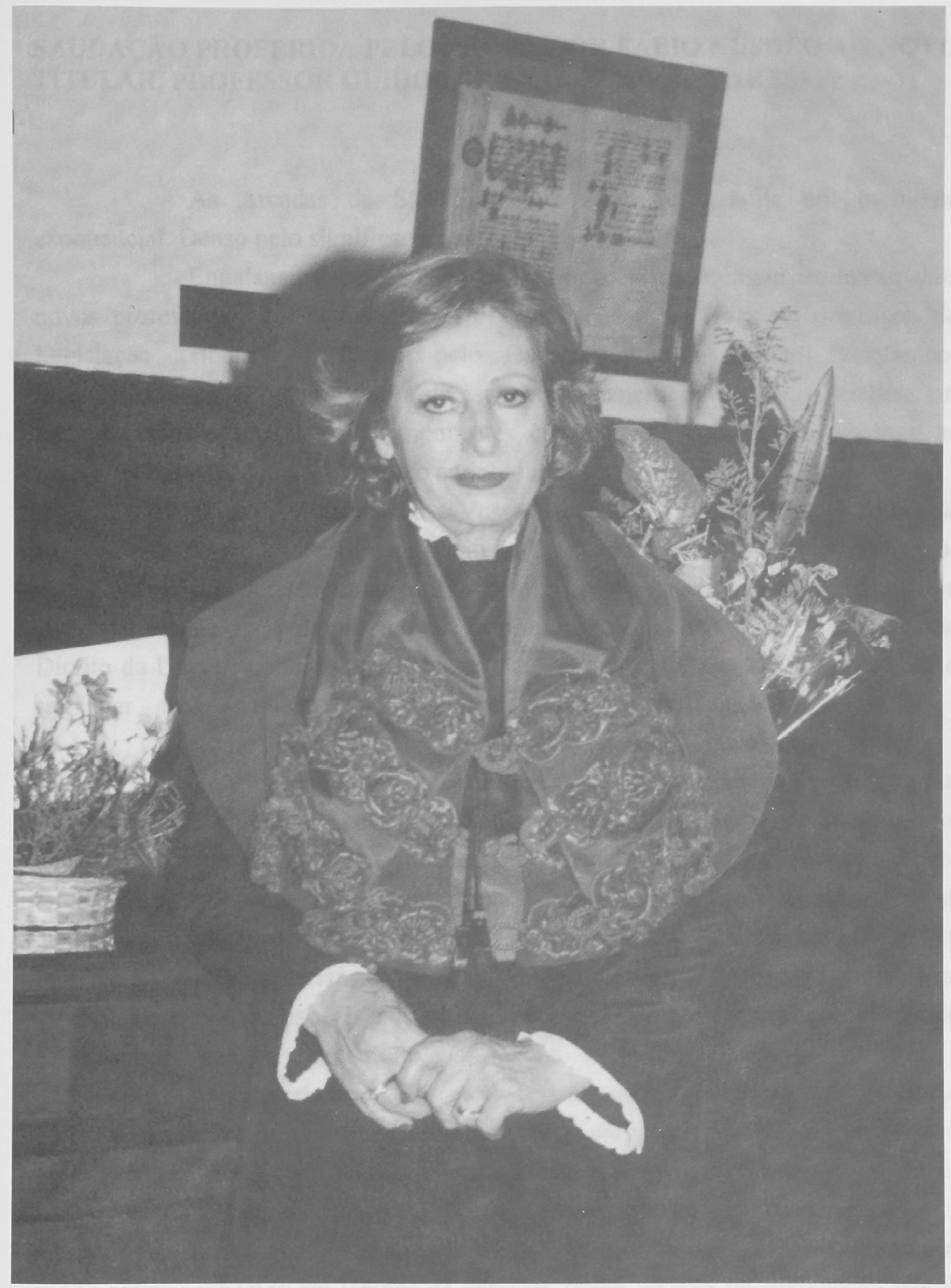

Professora Doutora Ivette Senise Ferreira 